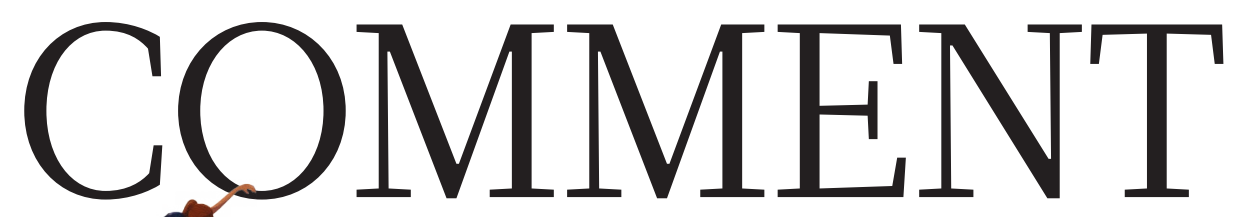

hOLIDAY READS Michael Mann revisits a Carl Sagan book for Donald Trump's times $\mathbf{p . 2 9}$
HOLIDAY READS How shipping shaped the first two waves of globalization $\mathbf{p . 2 9}$
REGULATION US agencies respond on genetically modified food $\mathbf{p . 3 1}$
OBITUARY Angela Brodie, pioneer of breast-cancer drugs, remembered p.32

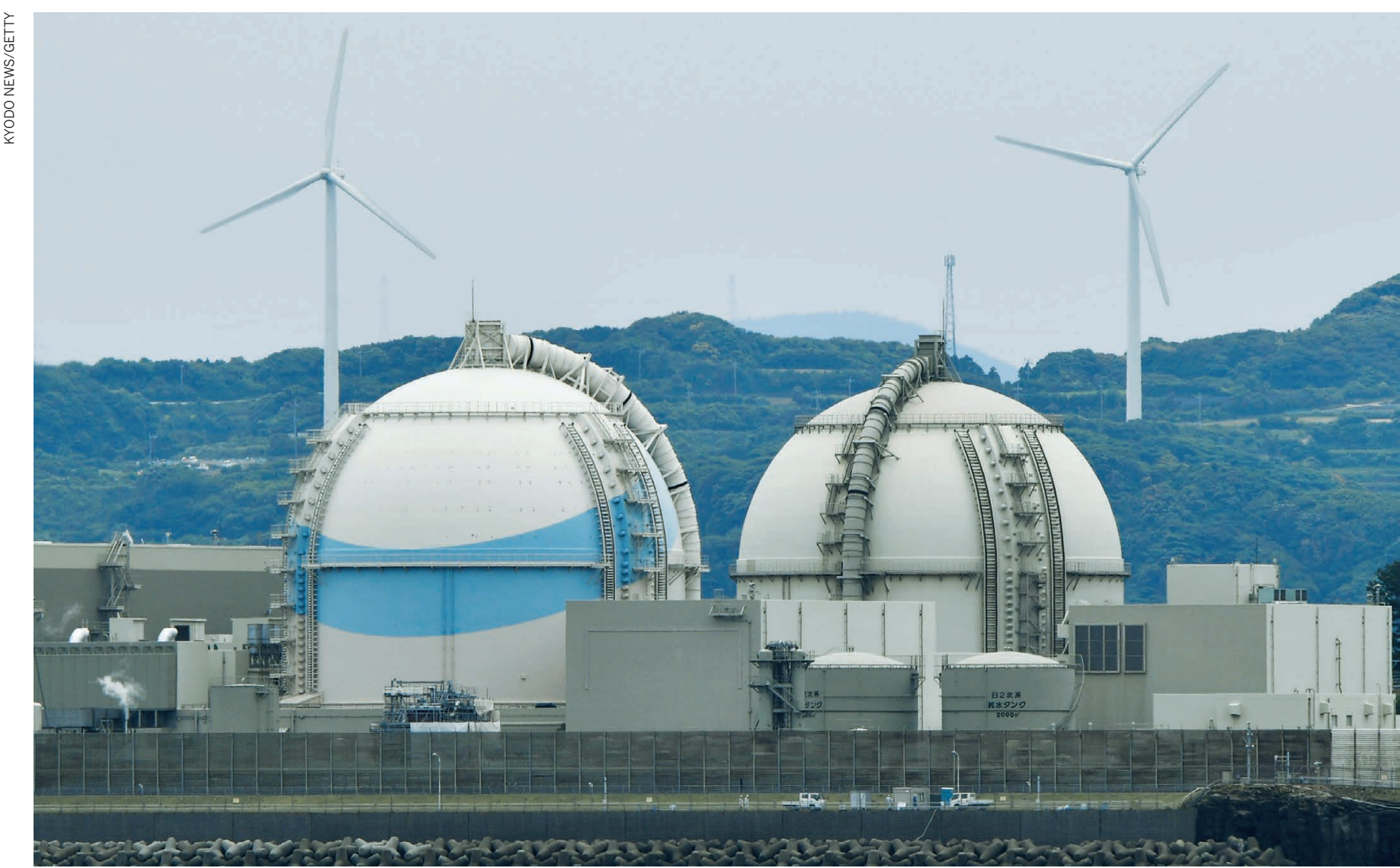

Japan is making efforts to restart some of its nuclear reactors, including reactors No. 3 and No. 4 at the Genkai power plant in Saga, Kyushu.

\title{
Prove Paris was more than paper promises
}

\section{All major industrialized countries are failing to meet the pledges they made} to cut greenhouse-gas emissions, warn David G. Victor and colleagues.

$\mathrm{B}$ eyond US President Donald Trump's decision in June to withdraw the United States from the 2015 Paris climate agreement, a more profound challenge to the global climate pact is emerging. No major advanced industrialized country is on track to meet its pledges to control the greenhouse-gas emissions that cause climate change.
Wishful thinking and bravado are eclipsing reality. Countries in the European Union are struggling to increase energy efficiency and renewable power to the levels that they claimed they would. Japan promised cuts in emissions to match those of its peers, but meeting the goals will cost more than the country is willing to pay. Even without Trump's attempts to roll back federal climate policy, the United States is shifting its economy to clean energy too slowly.

The Paris agreement offered, in theory, to reboot climate diplomacy by giving countries the flexibility to set their own commitments. As of July 2017, 153 countries have ratified the agreement - 147 of which have submitted pledges to reduce emissions, also known as nationally determined 
contributions. The idea is that as each country implements its own pledge, others can learn what is feasible, and that collaborative global climate protection will emerge. That logic, however, threatens to unravel because national governments are making promises that they are unable to honour.

Advanced industrialized nations are the key to getting the Paris agreement on track. These countries, conventionally the leaders on climate policy, have made pledges that will cost the most to deliver. They have the deepest pockets and are responsible for most of the emissions since the Industrial Revolution. Developing countries are of course vital to driving the deep worldwide reduction in emissions that is needed to stop global warming. But so far, such countries have set targets that will be much easier to achieve $^{1,2}$. Their policy priorities are closer to home, focusing on pressing problems such as cutting local air pollution and improving energy security.

We call on governments that want the Paris agreement to work to revisit their pledges now - well ahead of when the formal review process begins around 2020 - and to be honest about what they can and really will do. They should open up their pledges for voluntary peer review by other nations and by scientists. Only with greater transparency, anchored in reality, can bottom-up climate diplomacy yield true cooperation. Ambition is no substitute for action.

\section{MODEST PROGRESS}

Emission rates are falling in almost all advanced industrialized countries. But the declines are too slow to meet the pledges that governments made in Paris (see 'Climate shortfall'). Although the general story is the same, the details differ for each.

For example, in 2015, the administration of former president Barack Obama pledged to cut emissions in the United States to 26-28\% below 2005 levels by the year 2025. Yet the country was probably only ever on track to cut its emissions by $15-19 \%$. The energy markets are, of their own accord, substituting natural gas for coal; and policies that push renewable energy and energy efficiency are playing a part ${ }^{3}$. The assumptions about maximal carbon sequestration from forestry, which the US government submitted to the secretariat of the United Nations Framework Convention on Climate Change, can best be described as heroic. Even when these are combined with optimistically low assumptions about energy demand and the cost of clean energy, emissions are likely to decline, at most, to $23 \%$ below 2005 levels by 2025 (ref. 3).

Under Trump, the gap between what was promised and what will be achieved has widened as the federal government seeks to revoke the US Environmental

\section{CLIMATE SHORTFALL}

Emissions trajectories for three advanced industrialized regions show that enacted and pledged policies will be unable to deliver the ambitious cuts to emissions agreed under the ambitious cuts to emissions agreed under the 2015 Paris framework.

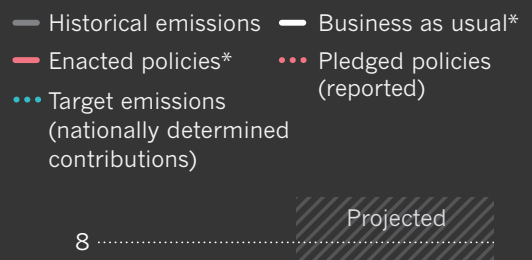

8
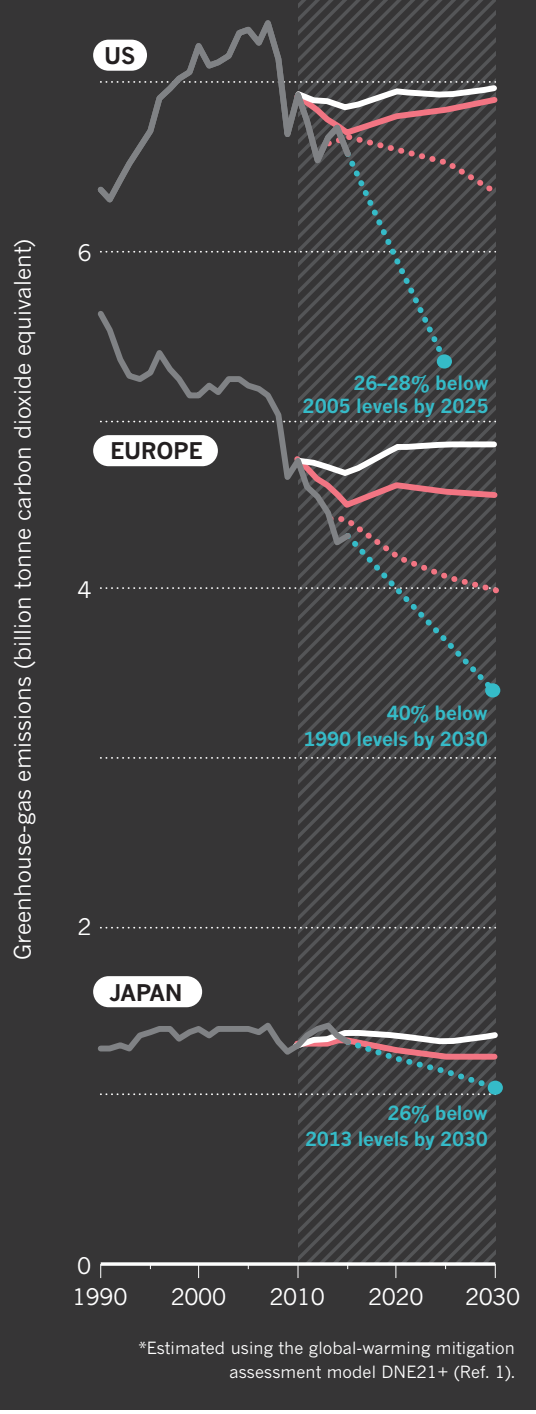

Protection Agency's Clean Power Plan, to roll back limits on the emission of the potent greenhouse gas methane and to reverse energy-efficiency policies ${ }^{4}$. Many companies, cities and states in the United States have vowed to keep cutting emissions but, for now, most of those are still just claims.

Japan pledged to cut emissions by a similar percentage to the United States: $26 \%$ below 2013 levels by the year 2030. But the Japanese economy is already more efficient than that of the United States - each dollar equivalent of economic output in Japan requires 40\% less energy, according to the International Energy Agency. Making an efficient system even more frugal will require a massive effort. The costs of meeting Japan's pledge are high $^{1}$, and they are poised to increase to levels that are unsustainable politically for industries that must be competitive worldwide. Programmes aimed at moving quickly to the most efficient equipment in the steel industry, for example, will force retirement of capital stock much faster than makes sense for the market.

In Japan, as in all industrialized countries, electricity is pivotal to efforts to control emissions. All told, Japan's pledge and associated policies would reduce electricity consumption by $17 \%$ below the level expected without new policies by the year 2030 - despite the fact that more sectors such as transport will use electricity.

In addition, the Japanese government is unlikely to meet its aim to supply $20-22 \%$ of electricity from carbon-free nuclear power by 2030 ; our analysis suggests that $15 \%$ is more likely. Today, just 5 of the country's 42 nuclear reactors are producing electricity. Efforts to restart more are mired in political and regulatory issues in the aftermath of the Fukushima Daiichi nuclear-reactor disaster.

The EU also faces a big gap between words and actions. Progress is being made through the region's emissions trading scheme (ETS), which should enable the power and industrial sectors to cut their greenhousegas emissions by $43 \%$ below 2005 levels by 2030 (see go.nature.com/2tk9yhh). As in the United States, most of this will come from switching from coal to gas, rather than constructing new renewable-energy or nuclear plants, or carbon capture and storage facilities ${ }^{5}$.

Europe's biggest problem lies in the 55\% of emissions that fall outside the ETS, which come from buildings, transport, agriculture and waste. The costs of changing these sectors could be high and the practical difficulties in implementation numerous. For example, European plans to shrink energy use by $27-30 \%$ by the year 2030 compared with the business-as-usual scenario are extremely ambitious. Progress is dogged by the weak building regulations of member countries, poor enforcement of minimum standards and double counting of energy savings from overlapping policies.

For new cars, tighter carbon dioxide performance standards and labelling requirements will probably reduce emissions, but a disparity remains between laboratory testing and real-world performance. For agriculture and forestry, the share of EU emissions is expected to double in the absence of coordinated mitigation. 
And investment is not on track to meet Europe's goal of supplying 27\% of energy from renewable sources by 2030; at best, current policies may deliver around $24 \%{ }^{6}$.

European woes are deepened by Brexit. It potentially leaves the departing United Kingdom without a host of useful climaterelated regulation - including the ETS. And it would deprive the EU of one of its hitherto forceful, ambitious and economically rational members ${ }^{7}$.

Other advanced industrialized countries present a similar story of public swagger and lagging implementation. In Australia, for example, a June 2017 review $^{8}$ into the future security of the country's electricity market recommended weak cuts to emissions that would make the overall Paris commitments difficult to meet. Mexico and South Korea have introduced schemes that levy charges on those who use energy and emit carbon dioxide, and other policies aimed at increasing energy efficiency and the adoption of cleaner energy. But emissions are not changing much in either country, calling their pledges into question. If South Korea mothballs many of its nuclear power plants, as the current government has suggested, the gap will only grow.

\section{SLOW MOVEMENT}

Underlying these gaps in action is a powerful political logic. Climate change is an issue of huge public interest, especially in countries in which governments feel they must be seen to lead on global solutions. It is easy for politicians to make promises to impatient voters and opposition parties. But it is hard to impose high costs on powerful, well-organized groups. No system for international governance can erase these basic political facts. Yet the Paris agreement has unwittingly fanned the flames by letting governments set such vague and unaccountable pledges.

Most pledges are almost silent on the range of policies being used, making it difficult to discern which are actually effective. The EU, for example, submitted little information about the complex pledgeimplementation process that is already under way. The gap between promise and action is especially large for the strategies that governments are using to boost energy efficiency, for which the real costs are often opaque. Equipment prices can be easily assessed but these are frequently only a fraction of the total deployment costs.

The pledges are impenetrable in other ways. Even the Obama administration, which vowed to set a high standard for openness, did not disclose the assumptions it used to model future emissions. More information is needed to evaluate the plausibility of carbon sequestration by forests, projected outcomes of climate policy and businessas-usual market trends - especially in light

of the change in US leadership.

Accountability is crucial to bottom-up diplomacy, yet inconvenient for governments that are focused on looking good. It also makes academic research more useful. For example, academics have built an array of energy models that compute the costs of controls. These can be central in the policy debates about how much nations are willing to spend to address climate change, as well as how such resources can be deployed most efficiently. However, the models rest on a huge number of assumptions about the design and implementation of policies, the availability of technologies and the structure of the economy that affect projected costs manyfold ${ }^{1,2,9}$. Ground truth will improve such models and help scientists and governments to reveal the true costs and benefits of action.

\section{FAST TRACK}

By design, the Paris framework is malleable ${ }^{10}$. Governments that want the agreement to work must urgently turn the pledging system, its linchpin, into an effective catalyst for international cooperation.

First, governments must shift the conversation towards concrete actions, and away from broad numerical targets for emissions such as percentage cuts below baselines. Pledges need to be longer and more

"Malking an efficient system even more frugal will require a massive effort." detailed, with extensive supporting information on who will do what by when, how they will do it and at what cost. Particular attention must be paid to what governments are doing to stimulate private investment in new technologies. Bold goals still matter, but facts matter more.

Second, more appropriate metrics, indicators and models are needed to track which policies are making a difference. Cost is one indicator for which better ties are needed between academic studies and the real world. Other indicators could include the diversion of trade and investment to 'dirty' industries with high carbon emissions elsewhere, such as offshore or out of state, which will be needed to align climate policy with policy on investment and trade. And metrics are needed for public investment in research and development. Overall, there must be a clearer mapping of pledged efforts to the impact on individual sectors.

Agreeing the correct indicators and standards for pledges will be impossible in the formal UN-based Paris framework because too many countries do not want candour ${ }^{2,9}$. One solution is for countries to volunteer to issue fresh pledges and to submit to detailed reviews of each other's policy efforts. China and the United States did this in October 2016, when they released mutual reviews of their efforts to reform fossil-fuel subsidies, as part of the Group of 20 (G20) nations. Further such demonstrations in the next year would help to jump-start the formal review processes envisioned under the Paris framework $^{10}$.

Third, a focus on the policies that actually work will make it easier to identify areas in which countries must collaborate more. Good candidates include measures to reduce the costs of renewable and efficient energy technologies; efforts to stem deforestation (such as that associated with the palm-oil industry); and ways to control soot particles and short-lived greenhouse gases such as methane. By focusing on such successes, governments, companies and other stakeholders will reap more tangible benefits from engaging in the Paris agreement.

Paris was a huge step forward. But the framework remains young, incomplete and fragile. Its benefits are still abstract to most stakeholders. The exit of the United States could multiply those troubles, or it could provide an opportunity to fix the looming problem of incredible goals.

David G. Victor is professor of international relations at the School of Global Policy and Strategy, University of California, San Diego, USA, and co-chair of the energy security and climate initiative at the Brookings Institution, Washington DC, USA. Keigo Akimoto is leader of the systems analysis group at the Research Institute of Innovative Technology for the Earth (RITE), Kyoto, Japan. Yoichi Kaya and Mitsutsune Yamaguchi are president and special adviser at RITE, Tokyo, Japan. Danny Cullenward is research associate at Near Zero, California, USA. Cameron Hepburn is professor of environmental economics at the University of Oxford, UK. e-mail:david.victor@ucsd.edu

1. Akimoto, K., Sano, F. \& Shoai Tehrani, B. Evolut Inst. Econ. Rev. 14, 193-206 (2017).

2. Aldy, J. et al. Nature Clim. Change 6, 1000-1004 (2016).

3. Larsen, J., Larsen, K., Herndon, W. \& Mohan, S. Taking Stock: Progress Toward Meeting US Climate Goals (Rhodium Group, 2016)

4. Larsen, K., Larsen, J., Herndon, W., Mohan, S. \& Houser, T. Taking Stock 2017: Adjusting Expectations for US GHG Emissions (Rhodium Group, 2017).

5. Drummond, P. \& Ekins, P. Clim. Pol. 17, S51-S71 (2017).

6. European Commission. Proposal for a Directive of the European Parliament and of the Council on the Promotion of the Use of Energy from Renewable Sources (European Commission, 2016).

7. Hepburn, C. \& Teytelboym, A. Oxford Rev. Econ. Pol. 33, S144-S154 (2017).

8. Commonwealth of Australia. Blueprint for the Future: Independent Review into the Future Security of the National Electricity Market (Department of the Environment and Energy, 2017).

9. Aldy, J. E. \& Pizer, W. A. Rev. Environ. Econ. Pol. 10 3-24 (2016).

10.Victor, D. G. Yale Environment 360 (2 June 2017); available at go.nature.com/2uxt8r6 